\title{
Entrepreneurial Orientation and e-Business Capabilities of Manufacturing SMEs: An Absorptive Capacity Lens
}

\author{
Louis Raymond \\ Université du Québec à Trois-Rivières \\ louis.raymond@uqtr.ca \\ Anne-Marie Croteau \\ Concordia University \\ anne-marie.croteau@concordia.ca
}

\author{
François Bergeron \\ Université du Québec \\ francois.bergeron@teluq.ca \\ Josée St-Pierre \\ Université du Québec à Trois-Rivières \\ josee.st-pierre@uqtr.ca
}

\begin{abstract}
This research uses the absorptive capacity (ACAP) concept as a theoretical lens to study the effect of $e$ business upon the competitive performance of SMEs, addressing the following research issue: To what extent are manufacturing SMEs successful in developing their potential and realized ACAP in line with their entrepreneurial orientation? A survey study of 588 manufacturing SMEs found that their e-business capabilities, considered as knowledge acquisition and assimilation capabilities have an indirect effect on their competitive performance that is mediated by their knowledge transformation and exploitation capabilities, and insofar as these capabilities are developed as a result of a more entrepreneurial orientation on their part. Finally, the effect of this orientation on the SMEs' competitive performance appears to be totally mediated by their ACAP.
\end{abstract}

\section{Introduction}

Since the turn of the century, many small and mediumsized enterprises (SMEs) have evolved in an increasingly complex business environment, characterized by the internationalization of markets and the need for greater efficiency, effectiveness, and competitiveness based on innovation and knowledge. This has put increasing pressure upon the management of these firms, especially manufacturing SMEs that must develop a capacity to compete globally [1] and in highly competitive environments [2]. In order to lower their operating costs, increase their productivity and the quality of their products and services, and to respond to the increased requirements of their customers and other business partners, a number of these firms have made sizable investments in implementing Internet-based web-technologies as the infrastructure for e-business applications [3].

To the extent that e-business is assimilated by the SME, it can significantly affect the firm's key business processes and relationships such as collaborating with business partners in the development of new products and servicing customers worldwide [4], and thus enable the firm's innovation and internationalization processes [5]. The ultimate goal is to achieve greater competitive performance by reaching out to larger markets with new or improved products [6]. This issue is tackled here by using the concept of absorptive capacity (ACAP) as a theoretical lens to study the effect of manufacturing SMEs' entrepreneurial orientation and e-business capabilities upon their competitive performance.

Absorptive capacity is defined as the firm's ability to identify external knowledge, assimilate it, and apply this new knowledge through innovation and other competitive strategies such as internationalization [7]. Zahra and George [8] further defined ACAP in terms of a potential and a realized capacity. Potential ACAP refers to the firm's knowledge identification and assimilation (KAA) capabilities. In this study, we focus on those capabilities based upon the electronic means with which the firm collaborates with partners, conducts commercial activities with outside parties, and supports its business intelligence activities, i.e. ebusiness capabilities [3,4,5]. Realized ACAP refers to the firm's knowledge transformation and exploitation (KTE) capabilities [9]. In this study, ww focus on those capabilities based upon the network, R\&D and marketing activities as well as the advanced manufacturing technologies put in place by the SME to leverage its relationships with its customers, suppliers and other partners, i.e. operational capabilities [2,6,9].

There is now some evidence that these capabilities have in fact become enablers of innovation and internationalization for manufacturing SMEs $[10,11,12]$. However, the development of information processing, learning and knowledge management capabilities by these firms is deemed to be strongly influenced by their adoption of an entrepreneurial strategic posture or orientation $[13,14,15]$. The SME's absorptive capacity and in turn its competitive 
performance are thus shaped by its entrepreneurial orientation $[16,17,18]$.

The preceding considerations give rise to the following research issue: To what extent are manufacturing SMEs successful in developing their potential and realized ACAP in line with their entrepreneurial orientation? Our study addresses this issue by attempting to answer the following three research questions:

- To what extent does a firm develop KAA capabilities in line with its entrepreneurial orientation?

- To what extent does the development of KAA capabilities by the firm and its entrepreneurial orientation influence the development of its KTE, and in so doing, build its absorptive capacity?

- To what extent does this influence contribute to the successful outcome of the firm's innovation and internationalization processes, that is, to its competitive performance?

In using the absorptive capacity lens to frame our research questions, we follow Zahra, and George's [19] view of ACAP as dynamic capability, which assumes knowledge management to be an "IT-driven capability", and we respond to Roberts et al.'s [20] appeal for researchers to "adequately conceptualize and describe the relationship between IT and absorptive capacity". In answer to these questions, this paper presents the results of a survey study of 588 manufacturing SMEs.

\section{Theoretical Framework}

Based on the absorptive capacity concept, this research explores how manufacturing SMEs with an entrepreneurial orientation, use their internal resources to transform external information with the support of IT and other capabilities into knowledge that can be used to enhance their competitive performance. Given this research issue, the theoretical choices were based on a close conceptual fit with Zahra and George's view of knowledge management $[8,19]$ and prior empirical evidence of this fit $[9,17,20]$.

\subsection{Entrepreneurial Orientation}

Entrepreneurial orientation (EO) has emerged as one of the most widely accepted concepts in the strategic management and entrepreneurship literatures [21]. It is defined as "a strategic organizational posture that captures the specific processes, practices and activities that enable firms to create value by engaging in entrepreneurial endeavors" [14]. Moreover, the behaviour of entrepreneurial firms has been conceptualized as having three components, namely innovativeness in their product-market offerings, risk taking in their business ventures, and proactiveness in their innovations [22], thus "beating competitors to the punch" [23]. As a well-established research construct, EO has often been applied as an antecedent or determinant of firm performance [24] and as a correlate or covariate of other related strategic constructs such as the firm's market orientation [25] and strategic capabilities [26].

IT capabilities are obviously needed to support knowledge management activities but their impact on organizational performance has yet to be clearly demonstrated [27]. Therefore, our research is designed to gather more insight on this issue and ascertain to what extent manufacturing SMEs with an entrepreneurial orientation can increase their performance by developing their KAA and KTE capabilities.

\subsection{Absorptive Capacity}

Absorptive capacity has its roots in the resource-based view which argues that organizational performance is enhanced through the development of capabilities [28]. This notion emerged when Cohen and Levinthal [7] attempted to understand how firms internalize the external information available to them. In order to do so, these authors drew a parallel with the manner in which individuals capture and process information in order to memorize such information and use it later.

ACAP was further conceptualized by Zahra and George [8] as a construct composed of potential and realized capacities. Potential ACAP is composed of knowledge acquisition and assimilation capabilities, where acquisition is the capability to identify and garner knowledge from external sources whereas assimilation refers to the internalization process by which this knowledge is interpreted and understood. On the other hand, realized ACAP is composed of knowledge transformation and exploitation capabilities, where transformation is characterized by the employees' ability to accept change in their tasks in order to make use of externally generated knowledge whereas exploitation embodies the result of enacting change and reaping benefits at the organizational level.

\subsubsection{KAA capabilities}

KAA capabilities, such as e-business, are considered here as being a form of the potential capacity defined by Zahra and George [8]. They are external relationship management IT capabilities [29,30] that are constitutive of an organization's absorptive capacity. In the context of SMEs [31,32,33], KAA capabilities usually take three basic forms.

A first type of KAA capabilities can be in the form of e-collaboration. It consists of integrating and 
sharing, through the Internet or extranets, information on the extended value chain linking the firm with its upstream and downstream business partners. This allows stakeholders within an industry, sector or network organization that share the same objectives to collaborate in the design, development, production and management of products and services at different stages of their life-cycle [34]. A second form of KAA capabilities is e-commerce. As this capability is transactional in nature, it has become easier for SMEs to develop successfully [35]. E-commerce capability refers to the buying and selling of goods and services through the Internet and Web-based technologies [36]. The last form is e-intelligence capability (or e-business intelligence) wherein the nature and breadth of information now available on the Internet allow the firm to scan its technological, commercial and competitive environment in search of ways and means to improve its operations and decision-making, and seek new product-market opportunities [37]. These capabilities, or KAA capabilities, when used in conjunction with complementary KTE capabilities $[38,39]$, form the organization's absorptive capacity. An appropriate choice of KAA capabilities helps the performance of manufacturing SMEs [11, 40].

\subsubsection{KTE capabilities}

KTE capabilities are considered here as being a form of realized capacity, as per Zahra and George [8]. They are similar to the "spanning" IT capabilities defined by Wade and Hulland [30], as they are the ones that transform information coming from outside the firm into meaningful knowledge by transferring it throughout the organization. Some authors argue that KTE capabilities are the "secret" ingredient to develop and maintain a competitive advantage [41]. KTE capabilities contribute to the firm's competitiveness by allowing it to allocate, exploit and coordinate its internal resources in a unique and coherent way [42].

Among the various types of KTE capabilities, the most relevant to SMEs are their networking [43], manufacturing [44], R\&D [7] and marketing capabilities [45,46]. Networking capabilities are specific to an organization and indicate its ability to exploit its relationships with its suppliers and other business partners $[43,45]$. They acknowledge the reality that firms depend on their ability to sustain relations with other organizations [47]. Manufacturing capabilities in terms of advanced manufacturing technologies (AMT) are developed in order to lower operating costs, increase productivity and quality, and respond to the increased requirements of customers and other business partners. SMEs' investments in manufacturing technologies such as computer-aided manufacturing (CAM) and manufacturing resource planning (MRP-II) are usually based on the scanning of their technological environment and their internal needs to innovate, to be more productive, and to grow $[48,49]$. Such capabilities help organizations to better transform and exploit information across functional areas [44]. For their part, R\&D capabilities are meant to allow the firm to renew its products and manufacturing processes, and thus increase its competitiveness [11]. Finally, marketing capabilities are defined as "integrative processes designed to apply the collective knowledge, skills, and resources of the firm to the market-related needs of the business, enabling the business to add value to its goods and services and meet competitive demands" [46]. These capabilities are used to deploy a stronger customer value and integrate all marketing related activities that would help organizations to develop a deeper understanding of their markets and customers' needs. Such integrated knowledge would allow them to enhance their performance [6].

\subsection{Competitive Performance}

Starting from Ansoff's [50] classic framework of generic growth strategies, the competitiveness of manufacturing SMEs can be envisioned in a number of non-mutually exclusive ways [51]. One way is through product innovation, that is, to create new products for present and prospective customers [52,53]. Another way is for the small manufacturer to develop new markets for its products, that is, to expand from a local, regional or national market to foreign markets, i.e. to internationalize [54]. Researchers in the strategic management, operations management and IS domains have thus conceptualized the competitive performance of SMEs on the basis of the "product-market" couple, that is, on the manufacturing firm's ability to renew its competitive offer by developing new products and to satisfy or create the demand for these products by developing new markets $[55,56,57,58]$.

\section{Research Model and Hypotheses}

Our research model, as illustrated in Figure 1, tries to answer the general research question which is: To what extent are manufacturing SMEs successful in developing their potential and realized absorptive capacity in line with their entrepreneurial orientation?

This issue is broken down in three ways. First, we are interested in finding out the extent to which SMEs develop their KAA capabilities in response to their entrepreneurial orientation. Secondly, we want to know if the firm's entrepreneurial orientation and development of KAA capabilities influence the development of its KTE capabilities. Thirdly, we 
wonder if the deployment of KTE capabilities in addition to an entrepreneurial orientation is linked to the firm's competitive performance. Therefore, our research will assess the role of entrepreneurial orientation and absorptive capacity in determining the competitive performance of SMEs. The dependent construct in this research is competitive performance and its antecedent constructs are entrepreneurial orientation, KAA capabilities and KTE capabilities while the control variables are the firm's size and the technological intensity of the industrial sector in which it operates. The ensuing research hypotheses are thus based on Zahra and George's [8] model of ACAP.

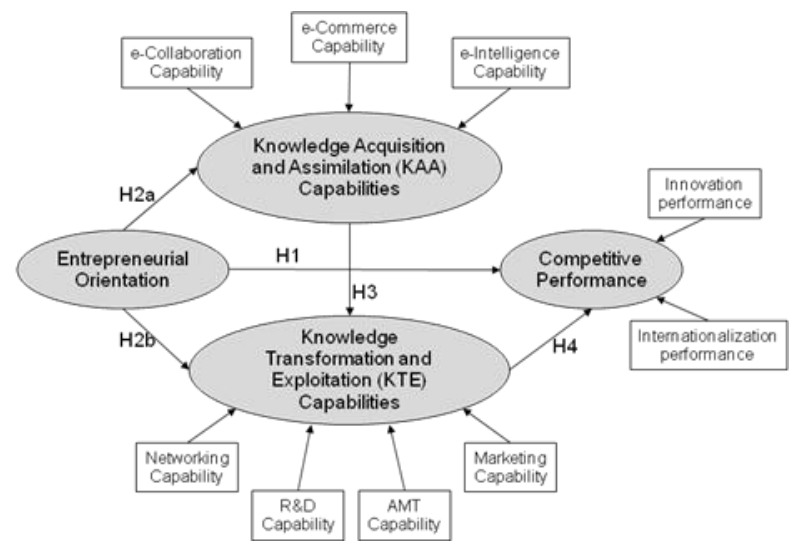

Figure 1: Research Model

The manner in which entrepreneurial orientation is conceptualized as well as the results of prior empirical studies on the EO-performance relationship strongly suggests that EO positively influences the competitive performance of SMEs, as defined in this study [18]. For instance, more proactive and risk-taking SMEs have been shown to be more innovative in product development [16]. A direct positive relationship between EO and competitive performance is thus hypothesized to increase the validity of the research model, and formulated as follows:

H1. The stronger the entrepreneurial orientation of a manufacturing SME, the greater its competitive performance.

It has been suggested previously that the firm's entrepreneurial orientation can enable it to effectively increase its absorptive capacity [17]. Indeed, the extent to which a SME can generate returns from its knowledge-based capital is dependent upon its ability to detect, seize and exploit new product-market opportunities [15]. Moreover, EO has been empirically identified as an antecedent to the SME's organizational learning and knowledge management processes and outcomes [13]. Hence the following hypotheses:
$H 2_{a}$. The stronger the entrepreneurial orientation of a manufacturing SME, the greater the deployment of its KAA capabilities.

$H 2_{b}$. The stronger the entrepreneurial orientation of a manufacturing SME, the greater the deployment of its KTE capabilities.

Following Helfat and Peteraf [59], we posit that KAA capabilities and KTE capabilities are positively linked because the latter are considered to be the result or output of the former. The realization of KAA capabilities and their value rest in creating a coherent configuration of KTE capabilities. Hence a third research hypothesis:

H3. The greater the deployment of a manufacturing SME's knowledge acquisition and assimilation (KAA) capabilities, the greater the deployment of its knowledge transformation and exploitation (KTE) capabilities.

The preceding hypothesis, again in line with Zahra and George's [8] conceptualization of ACAP, suggests that the KAA capabilities of SMEs indirectly influence the competitive performance of these firms by enabling their existing KTE capabilities to react in a more rapid and knowledgeable way to their entrepreneurial orientation. Therefore:

H4. The KTE capabilities of manufacturing SME mediate the relationship between its KAA capabilities and competitive performance.

\section{Method}

A questionnaire was developed as a survey research instrument. After pre-testing the instrument, the ownermanagers or CEOs of 3000 enterprises whose number of employees was less than 250, randomly chosen from a repertory of all manufacturing firms in the province of Quebec, Canada, were contacted by phone. Of these, 588 accepted the offer to answer the survey, thus giving a $19.6 \%$ response rate. The potential for nonresponse bias was ascertained through chi-square tests that confirmed the sample as being fairly representative of the survey's target population of SMEs in terms of firm size and industry. The mean number of employees for the sampled manufacturing SMEs is 51, with a maximum of 230 .

Entrepreneurial orientation was measured by using the instrument developed and validated by Covin and Slevin [60], in which the owner-manager is asked to characterize the firm's strategy, on nine 5-point Likert scales, in terms of innovativeness, proactiveness and risk-taking. A potentially important factor to control [61], the size of the firm was measured by the number of employees while the industry control variable was 
measured as the technological intensity of the industrial sector in which the firm operates (1: lowtech, 2: medium to low-tech, 3: medium to high-tech, 4: high-tech), following the OECD's [62] classification.

KAA capabilities of SMEs are assessed through three index measures by asking the SME ownermanagers to indicate the number of business activities for which the Internet and the Web are used in their organization. The activities proposed are grouped under three categories, namely e-collaboration (e.g. interacting with business partners in $R \& D$ to develop new products), e-commerce (e.g. selling products), and e-business intelligence (e.g. prospecting for new customers abroad). This categorization corresponds to Wade and Hulland's [30] characterization of outside-in IT capabilities and to the various levels of e-business development observed in SMEs [31,32].

KTE capabilities are assessed through four surrogate index measures drawn from the extant literature. Hence, the networking capability is ascertained through the business collaborations established in order to achieve greater efficiency in order to better response to the collected knowledge about the market needs [63], and improve competitiveness by transforming this new acquired knowledge [64]. The networking capabilities of manufacturing SMEs are thus estimated by the number of formal partnerships established for these purposes with various partners such as customers, suppliers and other third parties such as research centers [65]. Following prior studies $[66,67]$, the AMT capability are measured by the number of advanced manufacturing technologies and systems adopted by the SME, that is, using Kotha and Swamidass' [68] classification, product development technologies (CAD), process technologies (CAM), and computerbased production planning, control and logistics applications (ERP, production scheduling, quality assurance, bar-coding). $R \& D$ capability is measured by a commonly-used ratio: annual R\&D budget over total sales The marketing capability is estimated from the frequency with which activities such as customer satisfaction surveys, sales training, business intelligence, market study and prospecting activities are undertaken [69], that is, "outside-in" capabilities that help the firm to understand changes taking place in its markets [29].

Competitive performance is assessed through innovation performance and internationalization performance. Innovation performance is measured by the average percentage of sales attributed to new or modified products, this definition being appropriate to the reality of SMEs [70] and the one most accepted [53]. Given that exporting is still the prevalent mode of entry into foreign markets for manufacturing SMEs
[71], the indicators of internationalization performance measured is export intensity, using the commonly-used ratio of foreign sales to total sales [72].

\section{Results}

Structural equation modeling was used to validate the research model. To this effect, a component-based technique, PLS (partial least squares), was chosen for its robustness as it is much less exacting with regard to the distribution of residuals than covariance structure analysis techniques such as LISREL and EQS [73]. As often-used in IS research, PLS is more apt to handle measurement models that include endogenous formative constructs [74]. In this study, two of the research constructs are modeled as being formative rather than reflective (Figure 1), given their composite and multidimensional nature [75].

\subsection{Assessment of the Measurement Model}

The first step in the data analysis consists of simultaneously estimating the measurement and theoretical models using PLS. The psychometric properties of both the formative and reflective construct measures are thus assessed within the context of the structural model. As the standard reliability and validity criteria applicable to reflective constructs do not apply to formative constructs, one must first verify that there is no multicollinearity among each formative construct's indicators. In order to do so, one uses the variance inflation factor (VIF) statistic, the rule being that the VIF must not be greater than 3.3 in the case of formative constructs [76]. As shown in Figure 2, the VIF value for all of the formative indicators is below this threshold, confirming the absence of any multicollinearity.

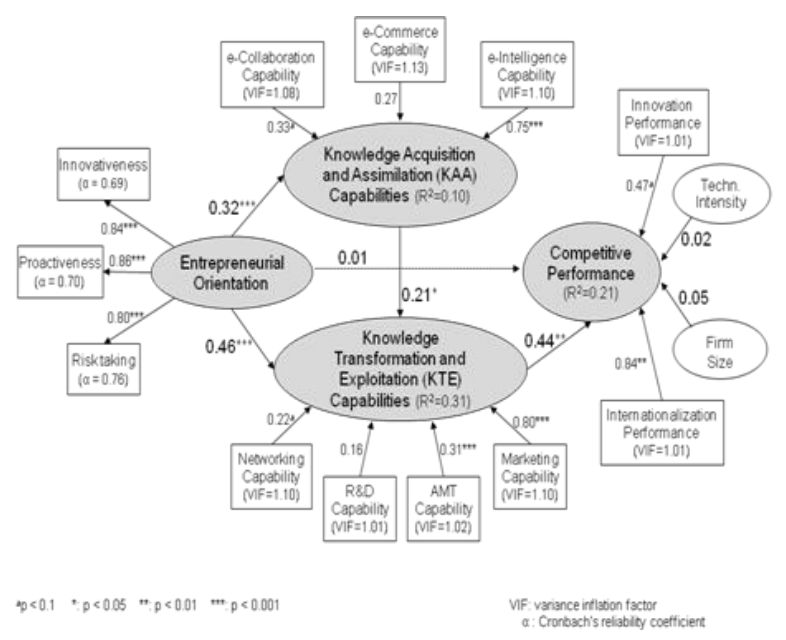

Figure 2: Test of the Research Model 
Having assessed the validity of the formative constructs, the unidimensionality and reliability of the reflective construct, entrepreneurial orientation, must then be evaluated. The three indicator loadings $(\lambda)$ on this construct being greater than 0.70 , its unidimensionality is confirmed. A composite reliability coefficient value of 0.87 , above the 0.80 threshold, confirms its internal consistency. There is also evidence of the convergent validity of the reflective construct because its average variance extracted (AVE), equal to 0.70 , is above the 0.50 threshold.

The last property to be verified is discriminant validity, showing the extent to which each construct in the research model is unique and different from the others. In the case of formative constructs, the fact that each shares less than 50\% variance with any other construct (inter-construct correlation inferior to 0.70), as seen in Table 1, is evidence of such validity [75]. For a reflective construct, discriminant validity is verified when the variance it shares with any other construct is less than its AVE, as confirmed in Table 1.

Table 1. Research Constructs' Intercorrelations

\begin{tabular}{|l|c|c|c|c|c|}
\hline \multicolumn{1}{|c|}{ Research constructs } & 1. & 2. & 3. & 4. & 5. \\
\hline 1. Entrepr. orientation & $.84^{\mathrm{a}}$ & & & & \\
2. KAA capabilities & .32 & - & & & \\
3. KTE capabilities & .53 & .36 & - & & \\
4. Competitive perform. & .25 & .14 & .46 & - & \\
5. Firm size & .06 & .03 & .10 & .06 & - \\
6. Technological intens. & .16 & .13 & .23 & .15 & .01 \\
\hline
\end{tabular}

${ }^{a}$ reflective construct: (average variance extracted) ${ }^{1 / 2}$

\subsection{Assessment of the Structural Model}

The research hypotheses were tested by assessing the path coefficients $(\beta)$ estimated by PLS, as presented in Figure 2. While PLS does not provide model fit indices, the performance of the structural model can be ascertained by the strength and significance of the path coefficients and by the proportion of construct variance $\left(\mathrm{R}^{2}\right)$ that is explained [77]. Moreover, one should consider as truly significant only those path coefficients greater than 0.20 because PLS tends to underestimate structural paths when compared with covariance structure-based techniques [78].

With regard to the first hypothesis, contrary to our initial expectations, entrepreneurial orientation was found to have no direct influence whatsoever upon competitive performance $(\beta=0.01, p>0.1)$. Instead, the effect of the SME's strategic posture on the outcome of its innovation and internationalization processes appears to be totally mediated by its ACAP.

Second, entrepreneurial orientation has a significant influence on KAA capabilities $(\beta=0.32, \mathrm{p}<0.001)$, thus providing adequate support for $\mathrm{H} 2_{\mathrm{a}}$. Furthermore, as expected by the strategic management literature, entrepreneurial orientation is found to directly influence KTE capabilities ( $\beta=0.46, p<0.001$ ), thus confirming $\mathrm{H} 22_{\mathrm{b}}$.

Third, KAA capabilities are found to have a significant positive influence on KTE capabilities $(\beta=$ $0.21, \mathrm{p}<0.05$ ), providing adequate support for $\mathrm{H} 3$. Furthermore, one can look at the weight $(\gamma)$ of each capability on its associated construct for some indication of the breadth and depth of this influence. Returning to Figure 2, one sees that that the KAA capability with the most influence is e-business intelligence $(\gamma=0.75, \mathrm{p}<0.001)$, and that among the KTE capabilities, the most influenced is the marketing capability $(\gamma=0.80, \mathrm{p}<0.001)$. Less influential is the e-collaboration capability $(\gamma=0.33, \mathrm{p}<0.1)$ and less influenced are the AMT $(\gamma=0.31, \mathrm{p}<0.01)$ and networking capabilities $(\gamma=0.22, \mathrm{p}<0.1)$. Finally, ecommerce is the least influential KAA capability $(\gamma=$ $0.27, \mathrm{p}>0.1)$ while $R \& D$ is the least influenced KTE capability $(\gamma=0.16, p>0.1)$.

As expected by the knowledge management literature, KTE capabilities were found to have a strong effect on competitive performance $(\beta=0.44, p<0.01)$. Given this significant effect, to examine the mediating role of KTE capabilities on the performance effects of KAA capabilities, an alternative research model was tested, adding a direct path between KAA capabilities and competitive performance. The added path coefficient was not significant $(\beta=-0.04, p>0.1)$ and provided no significant increase in the explained variance of competitive performance $\left(\mathrm{R}^{2}=0.212\right.$ versus 0.211 for the initial model). As further evidenced by a mediation test [79], the impact of the KAA capabilities on the SMEs' competitive performance was found to be fully mediated by the KTE capabilities, thus confirming H4.

In estimating the research model's overall validity, one finds that significant variance is explained in both KAA and KTE capabilities (10\% and 31\%), and in competitive performance $(21 \%)$. Finally, in the latter case, the size and industry control variables provide very little in added explained variance $(0.3 \%)$.

\section{Discussion}

Results indicate that the absorptive capacity level of manufacturing SMEs, as determined by their ability to integrate their KAA and KTE capabilities, significantly contributes to the competitive performance of these firms. Furthermore, entrepreneurial orientation is shown to be determinant of the absorptive capacity of these firms. These results confirm the relevance of the absorptive capacity lens in explaining the behavior of SMEs wanting to become "world-class" in the face of high product-market uncertainties. 
Hypothesis testing first revealed that the SME's entrepreneurial orientation is positively associated with its KAA capabilities. Thus, it is an appropriate action for SME managers to develop and deploy KAA capabilities that effectively enable its EO in reacting to its environment, especially when the uncertainty in this environment increases as a result of increased competitive pressures and a greater need for innovation and internationalization. This observation is confirmed by the quasi-null path coefficient linking KAA capabilities directly to competitive performance. In other words, a mere increase in the SME's KAA capabilities does not improve its competitive performance.

Further hypothesis testing pointed out that the SME's KAA capabilities must translate into appropriate KTE capabilities if the firm's competitive performance is to improve. KAA capabilities must "give rise" to KTE capabilities. Although the ecollaboration and e-commerce capabilities were significant factors, the e-business intelligence capability, which is an application dedicated to the acquisition and assimilation of knowledge, was the one that had the greatest weight on KAA capabilities. While KAA capabilities help to determine which specific KTE capabilities should be put in place, it is definitely through the choice of the specific KTE capabilities to be deployed that the organization can improve its competitive performance. What must be underlined is that the implementation of KAA capabilities, per se, is not sufficient to improve competitive performance. The SME's capacity to absorb new knowledge must therefore be processed through two types of absorptive capacity, that is, a potential capacity and a realized capacity [8].

It was also confirmed that KTE capabilities, when adapted to the context of the organization's KAA capabilities, positively influence the outcome of the SME's innovation and internationalization processes. In this case, marketing and AMT capabilities in particular were the KTE capabilities that truly determined the competitive performance of manufacturing SMEs. The firm's specific KTE capabilities must match its acquisition and assimilation capabilities in enabling its entrepreneurial orientation, that is, in implementing its strategic decisions. The specific capabilities required may vary among business sectors; for instance, advanced manufacturing capabilities could be replaced by customer-relationship management (CRM) capabilities for SMEs in the services sector.

\section{Contributions and Implications}

This study contributes to research in a number of ways. A first contribution lies in identifying the enabling role of the SME's entrepreneurial orientation with regard to its development of KAA and KTE capabilities for competitive purposes. Second, the absorptive capacity theoretical lens has been successfully applied to relate e-business and KTE capabilities to the competitive performance of manufacturing SMEs. This was made in light of Robert's et al.'s [20] plea for more research on the relationship between information systems and absorptive capacity. It also follows Zahra and George's [19] assumption that a greater comprehension of the role played by absorptive capacity in creating and sustaining a competitive advantage for the firm would be obtained by investigating this concept from multiple perspectives, including an IS perspective. The IT capabilities construct within this theoretical framework has been further refined by decomposing and regrouping its constituents into potential and realized components.

Another research contribution relates to the role of IT capabilities within a resource-based perspective. While a number of IS studies have taken this perspective to examine the impact of IT capabilities upon competitive performance, in the present study, the role of IT was conceptualized in terms of the strategic necessity perspective, i.e. using the absorptive capacity theoretical lens in terms of information technology's support of the SMEs' capabilities. This conceptualization views IT and e-business in particular, as playing an important role in the creation of competitive value if it is deployed to leverage the firm's capabilities [32].

A final contribution lies in extending the impact of absorptive capacity to a competitive process and outcome other than innovation, that is, internationalization. It is true that for SMEs, internationalization may be considered as a form of commercial innovation (developing new markets for one's products), but it differs significantly from product innovation in its strategic goals [80] and in the IT capabilities it necessitates [81].

This study also contributes to practice. The absorptive capacity lens can be used to plan the development of IT capabilities for manufacturing SMEs that aim to internationalize or are in the process of doing so, founded upon a two-level analytical approach. Potential absorptive capacity, based on knowledge acquisition and assimilation capabilities, illustrates the basic organizational capabilities that an international SME should first consider developing and deploying. Given the results of this investigation for manufacturing SMEs, these are, by order of importance, e-business intelligence, e-commerce, and e-collaboration capabilities. These capabilities constitute in turn the canvas onto which realized absorptive capacity, based on knowledge transformation and exploitation capabilities, identifies 
the befitting organizational capabilities that should then be developed and deployed.

\section{Limitations and Future Research}

This study has certain limitations that must be mentioned. While the studied sample of firms is representative of manufacturing SMEs in the province of Quebec, Canada, in terms of size and industry, it may have certain particularities linked to its technological, regional and national contexts that limit the generalization of the results to a wider global context. The index variables used to measure KAA and KTE capabilities may not possess sufficient breadth and depth. Moreover, a longitudinal study could reveal additional results that the present cross-sectional study cannot obtain, most notably a true causal link between the development of KAA capabilities and the successful internationalization of SMEs. Finally, alternative knowledge management capabilities and models [82] could be applied in future research.

Given the preceding limitations, future research should aim to better understand "how" KAA capabilities emerge and help build the absorptive capacity of small firms in the innovation and internationalization processes. Are these capabilities developed in alignment with the firm's entrepreneurial orientation, or are they rather adaptations of the innovation and international competencies and experience of SME owner-managers [83]? This also implies that future IT capability studies done in a SME context should take into account the potentially determining role played by these individuals [84].

\section{References}

[1] Lu, J.W. and Beamish, P.W. 2001. The internationalization and performance of SMEs, Strategic Management Journal (22), 565-586.

[2] Autio, E., George, G. and Alexy O., 2011. International entrepreneurship and capability development Qualitative evidence and future research directives, Entrepreneurship Theory and Practice (35), 11-37.

[3] Grandon, E. and Pearson, J.M. 2004. E-commerce adoption: Perception of managers/owners of small and medium sized firms in Chile, Communications of the Association for Information Systems (13), 81-102.

[4] Bharadwaj, A.S. 2000. A resource-based perspective on information technology capability and firm performance: An empirical investigation, MIS Quarterly (24:1), 169-196.

[5] Rhee, J.H. 2005. The Internet era and the international expansion process: The moderating role of absorptive capacity, Management International Review (45:3), 277 306.

[6] Nath, P., Nachiappan, S., Ramanathan, R. 2010. The impact of marketing capability, operations capability and diversification strategy on performance: A resourcebased view, Industrial Marketing Management (39), 317-329.

[7] Cohen, M.A. and Levinthal, D. 1990. Absorptive capacity: A new perspective on learning and innovation, Administrative Science Quarterly (35:1), 128-152.

[8] Zahra, S.A. and George, G. 2002a. Absorptive capacity: a review, reconceptualization, and extension, Academy of Management Review (27:2), 185-203.

[9] Cepeda, G. and Vera, D. 2007. Dynamic capabilities and operational capabilities: A knowledge management perspective, Journal of Business Research (60), 426437.

[10] Higón, D.A. 2012. The impact of ICT on innovation activities: Evidence for UK SMEs, International Small Business Journal (30:6), 684-699.

[11] Raymond, L. and St-Pierre, J. 2013. Strategic capability configurations for the internationalization of SMEs: A study in equifinality, International Small Business Journal (31:1), 82-102.

[12] Zhang, M., Sarker, S. and Sarker, S. 2008. Unpacking the effect of IT capability on the performance of exportfocused SMEs: A report from China, Information Systems Journal (18), 357-380.

[13] Brettel, M. and Rottenberger, J.D. 2013. Examining the link between entrepreneurial orientation and learning processes in small and medium-sized enterprises, Journal of Small Business Management (51:4), 471-490.

[14] Wales, W.J., Gupta, V.K. and Mousa, F.-T. 2013. Empirical research on entrepreneurial orientation: An assessment and suggestions for future research, International Small Business Journal (31:4), 357-383.

[15] Wiklund J and Shepherd D. 2003. Knowledge-based resources, entrepreneurial orientation, and the performance of small and medium-sized businesses. Strategic Management Journal (24:13), 1307-1314.

[16] Avlonitis, G.J. and Salavou, H. 2007. Entrepreneurial orientation of SMEs, product innovativeness, and performance, Journal of Business Research (60), 566575.

[17] Wales, W.J., Parida, V. and Patel, P.C. 2013. Too much of a good thing? Absorptive capacity, firm performance, and the moderating role of entrepreneurial orientation, Strategic Management Journal (34), 622-633.

[18] Su, Z., Xie, E. and Li, Y. 2011. Entrepreneurial orientation and firm performance in new ventures and established firms, Journal of Small Business Management (49:4), 558-577.

[19] Zahra, S.A. and George, G. 2002. The net-enabled business innovation cycle and the evolution of dynamic capabilities, Information Systems Research (13:2), 147150.

[20] Roberts, N., Galluch, P.S., Dinger, M. and Grover, V. 2012, Absorptive capacity and information systems research: Review, synthesis, and directions for future research, MIS Quarterly (36:2), 625-648, A1-A6.

[21] Covin, J.G. and Wales, W.J. 2012. The measurement of entrepreneurial orientation, Entrepreneurship Theory and Practice (July), 677-702.

[22] Lumpkin, G.T. and Dess, G.G. 1996. Clarifying the entrepreneurial orientation construct and linking it to 
performance, Academy of Management Review (21:1), 135-172.

[23] Miller D. 1983. The correlates of entrepreneurship in three types of firms. Management Science (29:7), 770791.

[24] Wiklund, J. and Shepherd, D. 2005. Entrepreneurial orientation and small business performance: A configurational approach, Journal of Business Venturing (20), 82-83.

[25] Kwak, H., Jaju, A., Puzakova, M. and Rocereto, J.F. 2013. The connubial relationship between market orientation and entrepreneurial orientation, Journal of Marketing Theory and Practice (21:2), 141-161.

[26] Stam, W. and Elfring, T. 2008. Entrepreneurial orientation and new venture performance: The moderating role of intra- and extra-industry social capital, Academy of Management Journal (51:1), 97111.

[27] Liu, H., Ke, W., Wei, K.K. and Hua, Z. 2013. The impact of IT capabilities on firm performance: The mediating roles of absorptive capacity and supply chain agility, Decision Support Systems (54), 1452-1462.

[28] Helfat, C.E. and Winter, S.G. 2011. Untangling dynamic and operational capabilities: Strategy for the (n)everchanging world, Strategic Management Journal (32), 1243-1250.

[29] Day, G.S. 1994. The capabilities of market-driven organizations, Journal of Marketing (58:4), 37-52.

[30] Wade, M. and Hulland, J., 2004. The resource-based view and information systems research: Review, extension and suggestions for future research, MIS Quarterly (28:1), 107-142.

[31] Levy, M. and Powell, P. 2003, Exploring SME Internet adoption: Towards a contingent model, Electronic Markets (13:2), 173-181.

[32] Raymond, L. and Bergeron, F. 2008. Enabling the business strategy of SMEs through e-business capabilities A strategic alignment perspective, Industrial Management \& Data Systems (108:5), 577-595.

[33] Zhu, K. and Kreamer, K. 2000. E-commerce metrics for Net-enhanced organizations: Assessing the value of ecommerce to firm performance in the manufacturing sector, Information Systems Research (18:5), 463-475.

[34] Croteau, A.-M., Léger, P.-M. and Cassivi, L. 2008. The role of life cycle concepts in the assessment of interorganizational alignment, Industrial Management \& Data Systems (108:2), 145-161.

[35] Simmons, G, Armstrong, G. and Durkin, M. 2011. An exploration of small business website optimization: Enablers, influencers and an assessment approach, International Small Business Journal (29:5), 534-561.

[36] Rayport, J. and Jaworski, B.J. 2001. E-Commerce. New York: McGraw - Hill Higher Education.

[37] Hill, J. and Scott, T. 2004. A consideration of the roles of business intelligence and e-business in management and marketing decision making in knowledge-based and high-tech start-ups, Qualitative Market Research: An International Journal (7:1), 48-57.

[38] Hitt, M.A., Tihanyi, L., Miller, T. and Connelly, B. 2006. International diversification: Antecedents, outcomes, and moderators, Journal of Management (32:6), 831-867.
[39] Zhu, K. 2004. The complementarity of information technology infrastructure and e-commerce capability: A resource-based assessment of their business value, Journal of Management Information Systems (21:1), 167-202.

[40] Knight, G.A. and Kim, D. 2009. International business competence and the contemporary firm, Journal of International Business Studies (40), 255-273.

[41] Pavlou, P.A. and El Sawy, O.A. 2006. From IT competence to competitive advantage in turbulent environments: The case of new product development, Information Systems Research (17:3), 198-227.

[42] Wu, S.J., Melnyk, S.A. and Flynn, B.B. 2010. Operational capabilities: The secret ingredient, Decision Sciences (41:4), 721-754.

[43] Human, G. and Naudé, P. 2009. Exploring the relationship between network competence, network capability and firm performance: A resource-based perspective in an emerging economy, Management Dynamics (18:1), 2-14.

[44] Banker, R.D., Bardhan, I.R., Chang, H. and Lin, S. 2006. Plant information systems, manufacturing capabilities, and plant performance, MIS Quarterly (30:2), 315-337.

[45] Greenley, G.E., Hooley, G.J. and Rudd, J.M. 2005. Market orientation in a multiple stakeholder orientation context: Implications for marketing capabilities and assets, Journal of Business Research (58), 1483-1494.

[46] Weerawardena, J. 2003. The role of marketing capability in innovation-based competitive strategy, Journal of Strategic Marketing (11:1), 15-35.

[47] Ritter, T., Wilkinson, I.F. and Johnston, W.J. 2002. Measuring network competence: Some international evidence, Journal of Business and Industrial Marketing (17:2/3), 119-138.

[48] Bartel, A., Ichniowski, C. and Shaw, K. 2007. How does information technology affect productivity? Plant-level comparisons of product innovation, process improvement, and worker skills, The Quarterly Journal of Economics (122:4), 1721-1758.

[49] Bhatt, G., Emdad, A., Roberts, N. and Grover, V. 2010. Building and leveraging information in dynamic environments: The role of IT infrastructure flexibility as enabler of organizational responsiveness and competitive advantage, Information \& Management (47), 341-349.

[50] Ansoff, H.I. 1957. Strategies for diversification, Harvard Business Review (35), 113-124.

[51] Raymond, L. and Croteau, A.-M. 2006. Enabling the strategic development of SMEs through advanced manufacturing systems: A configurational perspective, Industrial Management \& Data Systems (106:7), 10121032.

[52] Roper, S. and Love, J.H. 2002. Product Innovation and Small Business Growth: A Comparison of the Strategies of German, U.K. and Irish Companies, Research Policy (31), 1087-1102.

[53] Raymond, L. and St-Pierre, J. 2010. R\&D as a determinant of innovation in manufacturing SMEs: An attempt at empirical clarification, Technovation (30:1), 48-56. 
[54] Acs, Z., Dana, L.P. and Jones, M.V. 2003. Toward new horizons: The internationalization of entrepreneurship, Journal of International Entrepreneurship (1:1), 5-12.

[55] Jin, Y., Vonderembse, M., Ragu-Nathan, T.S. and Turnheim Smith, J. 2014. Exploring relationships among IT-enabled sharing capability, supply chain flexibility, and competitive performance, International Journal of Production Economics (153), 24-34.

[56] Nidumolu, S.R. and Knotts, G.W. 1998. The effects of customizability and reusability on perceived process and competitive performance of software firms, MIS Quarterly (22:2), 105-137.

[57] Rivard, S., Raymond, L. and Verreault, D. 2006. Resource-based view and competitive strategy: An integrated model of the contribution of information technology to firm performance, Journal of Strategic Information Systems (15:1), 29-50.

[59] Helfat, C.E. and Peteraf, M.A. 2003. The dynamic resource-based view: capability lifecycles, Strategic Management Journal (24), 997-1010.

[59] Tang, X. and Rai, A. 2012. The moderating effects of supplier portfolio characteristics on the competitive performance impacts of supplier-facing process capabilities, Journal of Operations Management (30), 85-98.

[60] Covin, J.G. and Slevin, D.P. 1989. Strategic management of small firms in hostile and benign environments, Strategic Management Journal (10), 75 87.

[61] Bharati, P. and Chaudhury, A. 2006. Studying the current status: Examining the extent and nature of adoption of technologies by micro, small and medium sized manufacturing firms in the greater Boston area, Communications of the ACM (49:10), 88-93.

[62] OECD, 2011. ISIC Rev.3 Technology Intensity Definition, Paris: OECD Publishing, http://www.oecd.org/science/innovationinsciencetechnol ogyandindustry/48350231.pdf.

[63] Street, C.T. and Cameron, A.-F. 2007. External relationships and the small business: A review of small business alliance and network research, Journal of Small Business Management (45:2), 239-266.

[64] Johanson, J. and Vahlne, J.-E. 2009. The Uppsala internationalization process model revisited: From liability of foreignness to liability of outsidership, Journal of International Business Studies (40), 14111431.

[65] Al-Laham, A. and Souitaris, V. 2008. Network embeddedness and new venture internationalization: Analyzing international linkages in the German biotech industry, Journal of Business Venturing (23), 567-586.

[66] Brandyberry, A., Rai, A. and White, G.P. 1999. Intermediate performance impacts of advanced manufacturing technology systems: an empirical investigation, Decision Sciences (30:4), 993-1020.

[66] Freel, M.S. 2005. Patterns of innovation and skills in small firms, Technovation (25), 123-134.

[67] Rai, A., Tang, X., Brown, P. and Keil, M. 2006. Assimilation patterns in the use of electronic procurement innovations: A cluster analysis, Information \& Management (43), 336-349.
[68] Kotha, S. and Swamidass, P.M. 2000. Strategy, advanced manufacturing technology and performance: empirical evidence from U.S. manufacturing firms, Journal of Operations Management (18:3), 257-277.

[69] Czarnitzki, D. and Spielkamp, A. 2003. Business service in Germany: bridges for innovation, The Service Industries Journal (23:2), 1-30.

[71] Armario, J.M., Ruiz, D.M. and Armario, E.M. 2008. Market orientation and internationalization in small and medium-sized enterprises, Journal of Small Business Management (46:4), 485-511.

[72] Ruigrok, W., Amann, W. and Wagner, H. 2007. The internationalization-performance relationship at Swiss firms: A test of the S-shape and extreme degrees of internationalization, Management International Review (47:3), 349-368

[73] Gefen, D., Straub, D.W. and Boudreau, M.-C. 2000. Structural equation modeling and regression: Guidelines for research practice, Communications of the Association for Information Systems (4:7), 1-76.

[74] Roberts, N. and Thatcher, J.B. 2009. Conceptualizing and testing formative constructs: Tutorial and annotated example, Data Base for Advances in Information Systems (40:3), 9-39.

[75] MacKenzie, S.B., Podsakoff, P.M. and Jarvis, C.B. 2005. The problem of measurement model misspecification in behavioral and organizational research and some recommended solutions, Journal of Applied Psychology (90:4), 710-730.

[76] Diamantopoulos, A. and Siguaw, J. 2006. Formative vs. reflective indicators in organizational measure development: A comparison and empirical illustration, British Journal of Management (17), 263-282.

[77] Chin, W.W. 1998. The partial least squares approach for structural equation modeling, in Modern Methods For Business Research, G.A. Marcoulides (ed.), Hillsdale, New Jersey: Lawrence Erlbaum Associates, 295-336.

[78] Chin, W. W. 1998. Issues and opinion on structural equation modeling, MIS Quarterly (22:1), vii-xvi.

[79] Lee, Y. and Chen, A. 2011. Usability design and psychological ownership of a virtual world, Journal of Management Information Systems (28:3), 269-307.

[80] OECD, 2005. Oslo Manual: Guidelines for Collecting and Interpreting Innovation Data, $3^{\text {rd }}$ edition, Paris: OECD Publishing.

[81] Bhatt, G.D. and Grover, V. 2005. Types of information technology capabilities and their role in competitive advantage: An empirical study, Journal of Management Information Systems (22:2), 253-277.

[82] Gold, A.H., Malhotra, A. and Segars, A.H. 2001. Knowledge management: An organizational capabilities perspective, Journal of Management Information Systems (18:1), 185-214.

[83] Casillas, J.C., Moreno, A.M., Acedo, F.J., Gallego, M.A. and Ramos, E. 2009. An integrative model of the role of knowledge in the internationalization process, Journal of World Business (44), 311-322.

[84] Hagen, B., Zucchella, A., Cerchiello, P. and De Giovanni, N. 2012. International strategy and performance - clustering strategic types of SMEs, International Business Review (21), 369-382. 